\title{
AVALIAÇÃO DA QUALIDADE DE SEMENTES DE SUCUPIRA-PRETA (Bowdichia virgilioides Kunth.) PELO TESTE DE RAIOS X
}

\author{
Evaluation of seed quality of black sucupira (Bowdichia virgilioides Kunth.) by $\mathrm{X}$ ray test
}

\author{
Keline Sousa Albuquerque1, Renato Mendes Guimarães ${ }^{2}$
}

\begin{abstract}
RESUMO
Injúrias representam um fator limitante para a viabilidade de sementes e, dependendo da sua intensidade, podem reduzir o seu vigor, produzindo plântulas fracas e, conseqüientemente, mais susceptíveis às condições adversas. Nesta pesquisa, foi verificada a eficiência do teste de raios X na avaliação de danos em sementes de sucupira-preta e sua relação com o teste de germinação. Inicialmente, as sementes foram expostas a diferentes intensidades de radiação por diferentes tempos, sendo, em seguida, as sementes divididas em três categorias, de acordo com as imagens visualizadas nas radiografias: sementes sem danos, com pequenos danos e danos severos. O experimento foi conduzido em esquema fatorial 3x3, correspondendo a três lotes e três categorias de sementes. As variáveis analisadas foram a porcentagem e índice de velocidade de germinação. Pelos resultados foi observado que a intensidade de 30 Kv por 45 segundos permite melhor visualização dos danos nas sementes de sucupira-preta, danos esses que afetam a germinação.
\end{abstract}

Termos para indexação: Germinação, injúria, semente florestal.

\begin{abstract}
Injuries represent a limitng factor for the seed viability. Depending on their intensity, the injuries might reduce seed vigour, produce weak seedlings. Consequently, they might be more susceptible to adverse conditions. In this research, the efficiency of X ray test was verifie to evaluate damage in seeds of black sucupira and its relation with germination test. Initially, seeds were exposed to different intensities of radiation for different periods. Next, seeds were separated in three categories according to the images obtained in radiographs: seeds without damage, seeds with little damage and seeds with severe damage. The experiment was conducted in factorial system $3 \times 3$, corresponding to three lots and three categories of seeds. The variable analyzed were percentage and germination speed index. It was verified that the intensity of $30 \mathrm{Kv}$ per 45 seconds allowed better visualization of damages in seeds of black sucupira. Damages affect wich severely seed germination.
\end{abstract}

Index terms: Germination, damages, forest seed.

(Recebido em 28 de abril de 2006 e aprovado em 13 de março de 2007)

\section{INTRODUÇÃO}

Injúrias representam um fator limitante para a viabilidade de sementes e, dependendo da sua intensidade, podem reduzir o seu vigor, produzindo plântulas fracas e, conseqüentemente, mais susceptíveis às condições adversas (CARVALHO \& NAKAGAWA, 2000). Entretanto, muitos desses danos não são possíveis de serem observados a olho humano, dificultando o descarte das sementes antes da semeadura e comprometendo a qualidade do lote.

$\mathrm{O}$ teste de raios X para a avaliação de danos em sementes tem sido utilizado com êxito, sendo recomendado pela ISTA (1993) que o considera um método rápido e não destrutivo, permitindo a análise da estrutura interna das sementes.

Aspectos morfológicos das sementes, possivelmente associados à viabilidade, podem ser avaliados pelo teste de raios X (COPELAND \& MCDONALD, 1985). A eficiência do teste de raios $\mathrm{X}$ para predeterminar a germinação das sementes foi observada para sementes de Lycopersicon lycopersicum (L.) Karsten (BURG et al., 1994), Zea mays L. (CARVALHO et al., 1999; CÍCERO et al., 1998; OBANDOFLOR, 2000), Peltophorum dubium (Sprengel) Taub. (OLIVEIRA, 2000) e Lithraea molleoides (Vell.) Engl. (MACHADO \& CÍCERO, 2002).

Sementes de espécies florestais são, quase sempre, alvo de danos ocasionados por insetos e fungos, processos de colheita, dentre outros (BATTISTI et al., 2000; MACHADO \& CÍCERO, 2002). Dessa forma, o teste de raios $\mathrm{X}$ tem sido recomendado como uma técnica promissora para o estudo de sementes florestais, contribuindo para o controle de qualidade dessas, pela seleção e descarte de sementes de má qualidade física e fisiológica. Entretanto, a eficiência do teste depende de procedimentos específicos para a espécie em estudo, como

${ }^{1}$ Doutoranda em Fitotecnia - Departamento de Agricultura/DAG - Universidade Federal de Lavras/UFLA - Cx. P. 3037 - $37200-000$ - Lavras, MG kelinealbuquerque@yahoo.com.br

${ }^{2}$ Doutor, Professor Adjunto - Departamento de Agricultura/DAG - Universidade Federal de Lavras/UFLA - Cx. P. 3037 - $37200-000$ - Lavras, MG renatomg@ufla.br 
a determinação do melhor tempo e intensidade de radiação a que as sementes ficam expostas durante a execução do teste.

A sucupira-preta é uma espécie arbórea pertencente à família Fabaceae com ampla dispersão pelo Brasil. É considerada uma planta pioneira e adaptada a terrenos secos e pobres (BRANDÃO \& FERREIRA, 1991; LORENZI, 1992). Sua madeira, por ser de alta densidade e longa durabilidade natural, é empregada na construção civil e na fabricação de móveis. É bastante utilizada em programas de reflorestamento e na recuperação de áreas degradadas de preservação permanente (LORENZI, 1992).

A propagação da sucupira-preta ocorre por sementes. Entretanto, essa espécie possui limitações quanto à disponibilidade de métodos para avaliação da qualidade de suas sementes, informações estas de relevante importância para otimização do processo de produção de mudas.

Diante do que foi exposto, objetivou-se verificar a possibilidade de utilização do teste de raios X na avaliação de danos internos em sementes de sucupira-preta e observar a relação desses danos com o teste de germinação.

\section{MATERIAL E MÉTODOS}

O experimento foi conduzido no Laboratório de Análise de Sementes do Departamento de Agricultura e no Laboratório de Analise de Sementes Florestais do Departamento de Ciências Florestais, da Universidade Federal de Lavras, Lavras, MG.

Foram utilizados três lotes de sementes de sucupirapreta de diferentes procedências: o lote A coletado no município de Crato, CE, no ano de 2001; o lote B na cidade de Boa Vista, RR e o lote $\mathrm{C}$ na região do Norte de Minas Gerais, ambos coletados em 2003. As sementes de cada lote foram armazenadas em sacos plásticos, tendo as do lote A sido mantidas em temperatura ambiente, enquanto que as do os lotes $\mathrm{B}$ e $\mathrm{C}$ foram mantidas em câmara fria com controle de temperatura e umidade.

O grau de umidade foi determinado pelo método da estufa a $105 \pm 3^{\circ} \mathrm{C}$ por 24 horas (BRASIL, 1992). Foram utilizadas duas repetições contendo um grama de sementes para cada lote e os resultados foram expressos em porcentagem.

\section{Teste de raios $X$}

A princípio foram realizados testes com o objetivo de selecionar os melhores tempos e intensidades de radiação para as sementes de sucupira-preta.

As sementes foram dispostas sobre fita adesiva transparente dupla face, aderida a uma placa de acrílico. Em seguida, as placas foram sobrepostas ao filme radiográfico Kodak, Min-R 2000 e expostos à radiação utilizando o equipamento de raios X Faxitron HP, modelo 43855A X. Submeteram-se as sementes às potências de 15, 20, 25, 30 e $60 \mathrm{Kv}$, por 20,35, 25, 45 e 60 segundos, respectivamente.

Determinadas as melhores condições radiográficas (30 Kv por 45 segundos), as sementes foram divididas em três categorias, de acordo com a morfologia interna observada nas radiografias: sementes sem danos, com pequenos danos (menos de $50 \%$ do embrião danificado) e sementes com danos severos (mais de $50 \%$ do embrião danificado), sendo, em seguida, submetidas ao teste de germinação.

\section{Teste de germinação}

Para cada categoria de sementes obtidas pelos raios $\mathrm{X}$ foi realizado o teste de germinação, considerando a porcentagem de plântulas normais.

Inicialmente, as sementes foram submetidas à superação da dormência com ácido sulfúrico concentrado por 8 minutos e, em seguida, foram colocadas em solução de carbonato de cálcio a $2 \%$, por 3 minutos, para neutralizar o efeito do ácido. Logo após, as sementes foram desinfestadas com hipoclorito de sódio a $2 \%$, por 2 minutos.

$\mathrm{O}$ teste de germinação foi conduzido em câmara de germinação tipo BOD, à temperatura alternada $20-30^{\circ} \mathrm{C}$, com fotoperíodo de 12 horas associado à temperatura mais elevada. As sementes foram semeadas em caixas plásticas tipo gerbox sobre papel mata-borrão, umedecidas com água numa quantidade correspondendo a 2,5 vezes o peso do papel. Foram utilizadas 4 repetições de 25 sementes em cada tratamento. Após 30 dias, obteve-se a porcentagem de germinação a partir da contagem do número de plântulas normais (BRASIL, 1999).

Conjuntamente com o teste de germinação foi avaliado o índice de velocidade de germinação a partir da contagem do número de sementes germinadas (MAGUIRRE, 1962), sendo as contagens realizadas diariamente durante 30 dias. Foi considerada semente germinada aquela com comprimento radicular maior do que $2 \mathrm{~mm}$.

\section{Procedimento estatístico}

O delineamento experimental utilizado foi o inteiramente casualizado, em esquema fatorial $3 \times 3$, referente a três categorias de sementes e três lotes. Os dados de germinação foram transformados em arcsen vx/100 e do IVG em vX+0,5, de acordo com Banzatto \& Kronka (1995) para aproximação da curva normal e submetidos à análise de variância utilizando-se o programa estatístico SISVAR (FERREIRA, 2003). A comparação das médias foi realizada pelo teste de Tukey, a 5\% de probabilidade. 


\section{RESULTADOS E DISCUSSÃO}

$\mathrm{Na}$ análise da variância para porcentagem de germinação e índice de velocidade de germinação, foi observada interação significativa entre as categorias dos danos detectados pelos raios $\mathrm{X}$ e os lotes utilizados (Tabela 1).

Tabela 1 - Resumo da análise de variância para porcentagem de germinação e índice de velocidade de germinação (IVG) de três lotes de sementes de sucupira-preta, analisados radiograficamente. UFLA, Lavras, MG, 2006.

\begin{tabular}{lccc}
\hline & & \multicolumn{2}{c}{ QM } \\
\hline FV & GL & Germinação & IVG \\
\hline Lote & 2 & $820,317891^{*}$ & $0,522785^{*}$ \\
Categoria & 2 & $14288,191447^{*}$ & $2,763598^{*}$ \\
Lote*categoria & 4 & $273,632062^{*}$ & $0,245394^{*}$ \\
Erro & 27 & 51,209751 & 0,009129 \\
\hline CV $(\%)$ & \multicolumn{1}{c}{18,87} & 6,82 \\
\hline
\end{tabular}

A intensidade de $30 \mathrm{Kv}$ por 45 segundos permitiu uma melhor visualização das estruturas internas das sementes de sucupira-preta. Na Figura 1, observam-se as radiografias de sementes das três categorias e as plântulas geradas no teste de germinação.

Melo (2005), estudando aquênios de Lychophora pinaster (Mart.), também obteve a melhor visualização da morfologia interna, utilizando a intensidade de $30 \mathrm{Kv}$ por 45 segundos, enquanto que Masetto (2005) utilizou a combinação de $50 \mathrm{Kv}$ por 60 segundos, para sementes de Eugenia handroana D. Legrand. Já Oliveira (2004) obteve melhor visualização das estruturas internas das sementes de Tabebuia serratifolia (Vahl) Nich. e Tabebuia impetiginosa (Martius ex A. P. De Candolle) Standl. com a intensidade de $55 \mathrm{Kv}$ por 25 segundos. A variação observada entre diferentes espécies em relação à intensidade e tempo de exposição das sementes à radiação está relacionada com diferenças na espessura, densidade e composição das sementes, dentre outras (ISTA, 1993).

Por ocasião da realização do teste de germinação, as sementes continham um teor de água por volta dos $10 \%$.

Nas Tabelas 2 e 3 podem ser observados os resultados referentes à porcentagem de germinação e IVG das sementes de sucupira-preta, nas três categorias selecionadas por meio do teste de raios $\mathrm{X}$ para os três lotes utilizados. As sementes da categoria sem danos tiveram germinação superior para os lotes A e C. Este mesmo comportamento foi verificado para sementes com pequenos danos, embora a redução da germinação tenha sido bastante drástica de uma categoria para outra. Sementes em que foram observados danos severos nas imagens radiográficas não originaram nenhuma plântula normal para o teste de germinação em todos os lotes utilizados.

O índice de velocidade de germinação (Tabela 3) seguiu a mesma tendência da geminação, ou seja ser reduzido na medida em que se aumentam os danos nas sementes. Maior velocidade foi observada nas sementes da categoria sem danos, com o lote A se destacando dentre os demais. Para as sementes da categoria danos severos, houve a redução da velocidade de germinação em todos os lotes estudados. Vale ressaltar que as sementes dessa categoria foram capazes de germinar, porém, resultaram em plântulas anormais.

$\mathrm{Na}$ Figura 2 observam-se os dados referentes à porcentagem de plântulas normais, anormais e sementes mortas de sucupira-preta, no teste de raios X. De uma forma geral, nas sementes sem danos foi observada maior porcentagem de plântulas normais, seguidas das sementes com pequenos danos. Já as sementes com danos severos não tiveram plântulas normais, gerando apenas plântulas anormais e sementes mortas. Foi observada, ainda, uma alta incidência de fungos na categoria de sementes com danos severos. Este fato indica a inviabilidade de sementes com mais de $50 \%$ do embrião danificado.

Oliveira et al. (2003) avaliando sementes de canafístula, obtiveram resultados semelhantes para a categoria de danos severos. Obando-Flor et al. (2004), estudando danos em sementes de soja também observaram baixa porcentagem de germinação para sementes com danos severos. Já Oliveira et al. (2004) estudando sementes de Tabebuia serratifolia e Tabebuia impetiginosa observaram que a maioria das sementes com defeitos originou sementes mortas ao final do teste de germinação evidenciando que os defeitos identificados nas radiografias afetam a qualidade de lotes de sementes e que a eliminação dessas sementes defeituosas poderá favorecer a melhoria na qualidade física e fisiológica de lotes de sementes.

Segundo Carvalho \& Nakagawa (2000), injúrias podem provocar danos no tegumento que facilitam o acesso de microrganismos patogênicos ao interior das sementes, resultando na morte das mesmas.

$\mathrm{O}$ teste de raios $\mathrm{X}$ de sementes de sucupira-preta, quando relacionado com o teste de germinação, pode auxiliar na avaliação da qualidade física das sementes. Marcos Filho (2005) descreve que testes que envolvem aspectos morfológicos ou características físicas das sementes, possivelmente, estão relacionados ao vigor. 
A
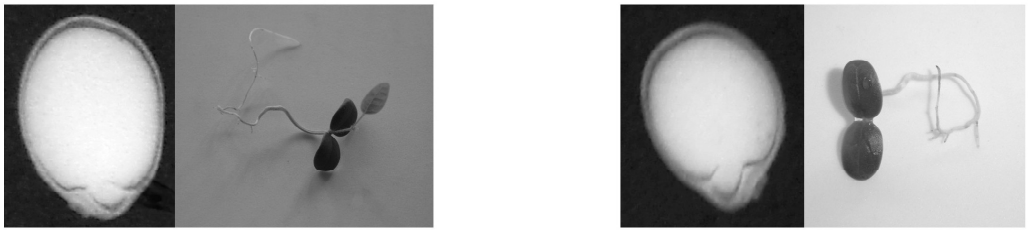

Plântula normal

B
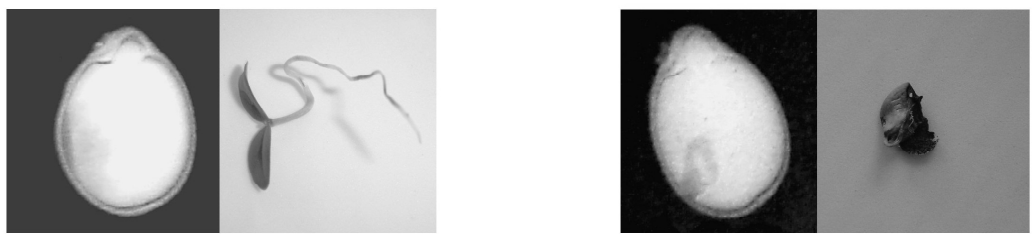

Plântula anormal
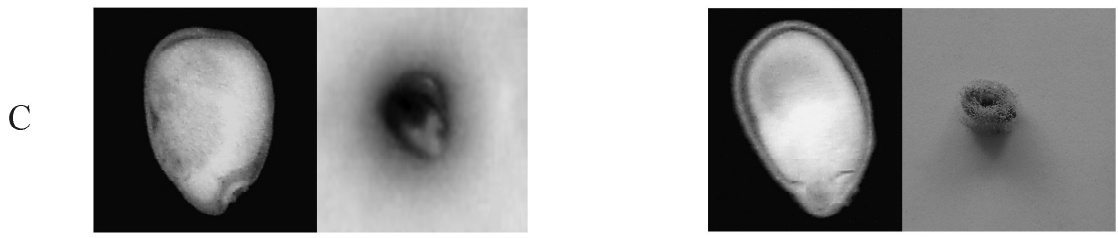

Semente morta

Figura 1 - Imagens radiográficas de sementes de sucupira-preta e suas respectivas plântulas resultantes do teste de germinação. (A) sem danos, (B) pequenos danos e (C) danos severos. UFLA, Lavras, MG, 2006.

Tabela 2 - Porcentagem de germinação de três lotes de sementes de sucupira-preta separados em três categorias, de acordo com a análise radiográfica. UFLA, Lavras, MG, 2006.

\begin{tabular}{cccc}
\hline & \multicolumn{3}{c}{ Categoria } \\
\cline { 2 - 4 } Lotes & Sem danos & Pequenos danos & Danos severos \\
\hline A & $94 \mathrm{~A} \mathrm{a}$ & $56 \mathrm{AB} \mathrm{b}$ & $0 \mathrm{Ac}$ \\
$\mathrm{B}$ & $86 \mathrm{~B} \mathrm{a}$ & $36 \mathrm{~B} \mathrm{~b}$ & $0 \mathrm{~A} \mathrm{c}$ \\
$\mathrm{C}$ & $96 \mathrm{~A} \mathrm{a}$ & $65 \mathrm{~A} \mathrm{~b}$ & $0 \mathrm{~A} \mathrm{c}$ \\
\hline
\end{tabular}

Médias seguidas pela mesma letra, maiúscula na coluna e minúscula na linha, não diferem entre si, a 5\% de probabilidade, pelo teste de Tukey.

Tabela 3 - Índice de velocidade de germinação de três lotes de sementes de sucupira-preta separados em três categorias, de acordo com a análise radiográfica. UFLA, Lavras, MG, 2006.

\begin{tabular}{cccc}
\hline & \multicolumn{3}{c}{ Categoria } \\
\cline { 2 - 4 } Lotes & Sem danos & Pequenos danos & Danos severos \\
\hline A & $4,36 \mathrm{~A} \mathrm{a}$ & $2,52 \mathrm{~A} \mathrm{~b}$ & $0,25 \mathrm{~A} \mathrm{c}$ \\
$\mathrm{B}$ & $1,47 \mathrm{C} \mathrm{a}$ & $0,96 \mathrm{~B} \mathrm{~b}$ & $0,39 \mathrm{~A} \mathrm{c}$ \\
$\mathrm{C}$ & $2,62 \mathrm{~B} \mathrm{a}$ & $2,37 \mathrm{~A} \mathrm{a}$ & $0,11 \mathrm{~A} \mathrm{~b}$ \\
\hline
\end{tabular}

Médias seguidas pela mesma letra, maiúscula na coluna e minúscula na linha, não diferem entre si a 5\% de probabilidade pelo teste de Tukey. 


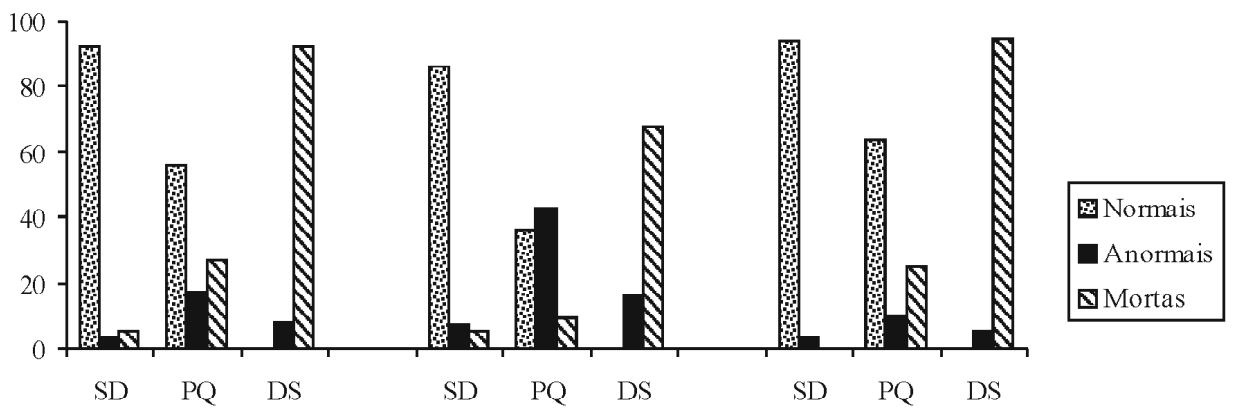

Figura 2 - Porcentagem média de plântulas normais, anormais e sementes mortas obtidas no teste de germinação para as categorias, de acordo com a análise radiográfica para sementes de sucupira-preta. SD (sem danos), PD (pequenos danos) e DS (danos severos). UFLA, Lavras, MG, 2006.

\section{CONCLUSÃO}

A utilização de $30 \mathrm{Kv}$ por 45 segundos permite a visualização de danos internos nas sementes de sucupirapreta.

O teste de raios $\mathrm{X}$ é eficiente na avaliação da extensão de danos em sementes de sucupira-preta.

Os danos na morfologia interna visualizados em radiografias, classificados como severos (mais de 50\% da área do embrião danificada) afetam a germinação das sementes.

\section{REFERÊNCIAS BIBLIOGRÁFICAS}

BANZATTO, D. A.; KRONKA, S. N. Experimentação agrícola. 3. ed. Jaboticabal: FUNEP, 1995. 247 p.

BATTISTI, A.; CANTINI, R.; FECI, E.; FRIGIMELICA, G.; GUIDO, M.; ROQUES, A. Detection and evaluation of seed damage of cypress, Cupressus sempervirens L., in Italy. Seed Science and Technology, Zurich, v. 28, n. 3, p. 729738, 2000.

BRANDÃO, M.; FERREIRA, P. B. D. Flora apícola do cerrado. Informe Agropecuário, Belo Horizonte, v. 15, n. 168, p. 4-8, 1991.

BRASIL. Ministério da Agricultura e Reforma Agrária. Regras para análises de sementes. Brasília, DF: SNDA/ DNDV/CLAV, 1992. 365 p.

BURG, W. J. van der; AARTSE, J. W.; ZWOL, R. A. van; JALINK, H.; BINO, R. J. Predicting tomato seedling morphology by X-ray analysis of seeds. Journal American Society for Horticultural Science, Alexandria, v. 119, n. 2, p. 258-263, Mar. 1994.
CARVALHO, M. L. M. de; AELST, A. C. van; ECK, J. W. van; HOEKSTRA, F. A. Pré-harvest stress crack in maize (Zea mays L.) kernels as characterized by visua, X-ray and low temperature scanning electron microscopical analysis: effect on kernel quality. Seed Science Research, Wallingford, v. 9, n. 3, p. 227-236, Sept. 1999.

CARVALHO, N. M.; NAKAGAWA, J. Sementes: ciência, tecnologia e produção. Jaboticabal: FUNEP, 2000. 588 p.

CÍCERO, S. M.; HEIJDEN, G. W. A. M. van der; BURG, W. J. van der; BINO, R. J. Evaluation of mechanical damage in seeds of maize (Zea mays L.) by X-ray and digital imaging. Seed Science and Technology, Zurich, v. 26, n. 3, p. 603612, 1998.

COPELAND, L. O.; McDONALD, M. Principles of seeds science and technology. New York: Macmillan, 1985. 321 p.

FERREIRA, D. F. SISVAR 4.6 sistema de análises estatísticas. Lavras: UFLA, 2003.

INTERNATIONAL SEED TESTING ASSOCIATION. International rules for seed testing. Seed Science and Technology, Zurich, v. 21, p. 363, 1993. Supplement.

LORENZI, H. Árvores brasileiras: manual de identificação e cultivo de plantas arbóreas nativas no Brasil. Nova Odessa: Plantarum, 1992. 368 p.

MACHADO, C. F.; CÍCERO, M. S. Metodologia para a condução do teste de germinação e utilização de raios-X para a avaliação da qualidade de sementes de aroeira-branca (Lithraea molleoides (Vell.) Engl.). Informativo ABRATES, São Paulo, v. 12, n. 123, p. 28-34, 2002. 
MAGUIRRE, J. D. Speed of germination aid in selection and evaluation for seedling and vigour. Crop Science, Madison, v. 2, n. 2, p. 176-177, Mar./Apr. 1962.

MARCOS FILHO, J. Avaliação do potencial fisiológico de sementes. In Fisiologia de sementes de plantas cultivadas. Piracicaba: FEALQ, 2005. p. 459-495.

MASETTO, T. E. Estudo da sensibilidade à dessecação em sementes de Eugenia handroana D. Legrand (Myrtaceae). 2005. 60 p. Dissertação (Mestrado em Engenharia Florestal) - Universidade Federal de Lavras, Lavras, 2005.

MELO, P. R. B. de. Germinação e armazenamento de aquênios de arnica (Lychnophora pinaster Mart.) coletados em diferentes estádios de maturação. 2005. Dissertação (Mestrado em Fitotecnia) - Universidade Federal de Lavras, Lavras, 2005.

OBANDO-FLOR, E. P. Danos internos de secagem avaliados pelo teste de raios- $X$ e seus efeitos na qualidade de sementes de milho (Zea mays L.) armazenadas. 2000. 62 p. Dissertação (Mestrado em Fitotecnia) - Universidade Federal de Lavras, Lavras, 2000.

OBANDO-FLOR, E. P.; CICERO, S. M.; FRANCA NETO, J. B.; KRZYZANOWSKI, F. C. Avaliação de danos mecânicos em sementes de soja por meio da análise de imagens. Revista Brasileira de Sementes, Brasília, v. 26, n. 1, p. 68-76, 2004.

OLIVEIRA, L. M. de. Avaliação da qualidade de sementes de canafístula (Peltophorum dubium (Sprengel) Taubert) pelos testes de germinação, tetrazólio e raios-x. 2000. 111 p. Dissertação (Mestrado em Engenharia Florestal) Universidade Federal de Lavras, Lavras, 2000.

OLIVEIRA, L. M. de. Avaliação da qualidade de sementes de Tabebuia serratifolia Vahl Nich. e Tabebuia impetiginosa (Martius Ex A. P. De Candolle Standley) envelhecidas natural e artificialmente. 2004.160 p. Tese (Doutorado em Fitotecnia) - Universidade Federal de Lavras, Lavras, 2004.

OLIVEIRA, L. M. de; CARVALHO, M. L. M. de; DAVIDE, A. C. Utilização do teste de raios-X na avaliação da qualidade de sementes de canafístula (Peltophorum dubium (Sprengel) Taubert). Revista Brasileira de Sementes, Brasília, v. 25, n. 1, p. 116-120, 2003

OLIVEIRA, L. M. de; CARVALHO, M. L. M. de; GUIMARÃES, R. M.; MASETTO, T. E. Avaliação da qualidade de sementes de Tabebuia serratifolia Vahl Nich. e Tabebuia impetiginosa (Martius Ex A. P. de Candolle) Standley - (bignoniaceae) pelo teste de raios X. Revista Brasileira de Sementes, Brasília, v. 26, n. 2, p. 138-143, 2004. 